\title{
Mechanical Design and Stress Analysis of Threaded Dental Implants along the Implant-Bone Interface
}

\author{
R. S. Jadhav ${ }^{1}$, P.N. Dhatrak ${ }^{2}$, V. K. Kulloli ${ }^{1}$ \\ (Dept. of Mechanical Engg. NBN Sinhgad School of Engineering, Ambegaon Bk. Pune- 411046, India) \\ ${ }^{2}$ (Dept. of Mechanical Engg, MAEER'S MIT, Pune-411038, India)
}

\begin{abstract}
In this following work, distribution of stresses along the implant-bone interface is computed by performing $3 D$ finite element analysis on commercially available dental implant system. The analysis of stresses is mainly focused at the implant-bone interface specifically at the neck region i.e. proximal zone. The effect of various thread parameters like thread pitch, and depth were studied on the stress distribution along the implantbone interface
\end{abstract}

Keywords - Dental implants, Finite Element Analysis, Types of threads, thread profiles.

\section{INTRODUCTION}

Threaded dental implants made of Titanium, which is a biocompatible material shown in fig. 1 are used as a prosthetic replacement for the affected tooth due to accidental injury, oral infection, deformities at the time of birth. It is necessary to avoid implant failure to reduce possibility of future retreatment. The response of bone to foreign insert is a critical phenomenon and the long-term effects of stresses produced are uncertain. The important factors that affect the success of implants are the stress values and stress distribution at the boneimplant interface. Due to overstress, bone cells start dying, which leads to bone resorption and finally causes implant failure. Most of the researchers have focused on parameters like length and diameter of dental implant for evaluation of stresses and stress distribution at implant-bone interface using finite element analysis [1][2][3]. The aim of this work is to analyze the stresses at the implant-bone interface and to minimize this stresses by deriving alternative implant thread profiles parameters. Dental implant system comprises of the following components viz. implant, abutment, fitting screw, and crown.

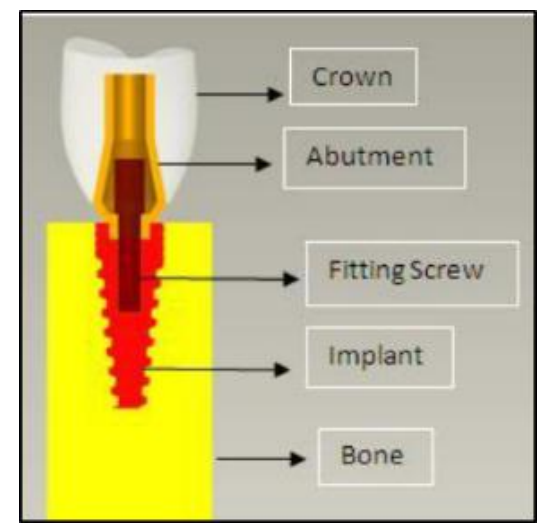

Fig 1. Dental Implant System

In this work, 3D finite element analysis is performed on commercially available dental implants with Vee threads. Number of iterations are carried out to find the best thread profile by varying the pitch and depth of the thread. Objectives of the current work is to carry out 3D finite element analysis on commercially available dental implants to analyze stresses along the implant-bone interface using commercial softwares, to study and analyze the stress distribution at the implant-bone interface and to carry out FEA based iterations by varying the thread parameters and find the best thread profile that will reduce the stress around the implant-bone interface. Implant specification preferred for the study are mentioned below,

Model No. 13.5 x $13 \mathrm{~mm}$

$5^{\text {th }}$ National Conference RDME 2016, 10-11 $1^{\text {th }}$ March 2016. 
Model No. 2 Dia. $3.5 x$ length 10

Model No. 3 Dia. $4 x$ length 11.5

Model No. 4 Dia. $4 x$ length 10

\section{MATERIALS AND METHODS}

2.1 Computer aided design and finite element modelling

The dimensions of the commercial dental implants were taken from the Optical Profile Projector. THE 3D CAD models was constructed by Creo Parametric software. The Finite Element Analysis was carried out using ANSYS 14.0. The Schematic illustration of thread profile properties used in study is shown in Figure 2.

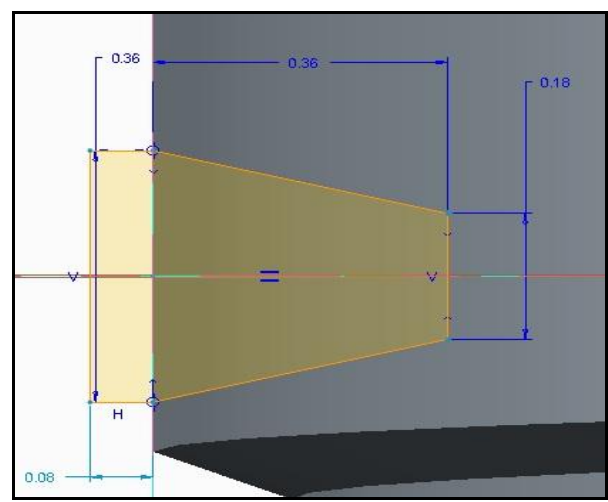

Fig 2. Schematic illustration of thread profile properties used in study

3D meshing was carried out by using HYPERMESH software. The static stress analysis of the Implant bone system was carried out by using Solid187 (10 noded quadrilateral element) and Shell181(4 noded linear element) for implant and crown modelling respectively. 10 noded tetra hedral element is three-dimensional solid element which has a quadratic displacement behavior and is well suited in modelling irregular meshes such as that produced by CAD programs [4]. Element size for the implant and bone modelling is kept $0.1-0.3 \mathrm{~mm}$. As results accuracy is not required at the abutment, intermediate screw and outer cortical bone so the mesh is kept course, the element size for the abutment, fitting screw is kept $0.5 \mathrm{~mm}$. The total number of nodes and elements for the FE models are approximately about 19000 and 415000 respectively. The cut section of the meshed model is shown in the figure 3 .

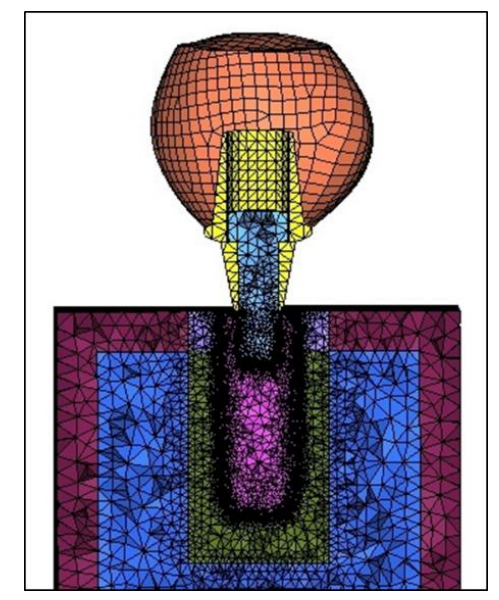

Fig 3. Cut section of the FE model

\subsection{Material properties}

The material properties of Titanium alloy are given as linear isotropic with Young's modulus of $110000 \mathrm{MPa}$ and Poisson's ratio of 0.3 . The material properties of mandible are actually non-homogeneous and anisotropic. Many of the three dimensional models employ orthotropic material properties for cortical bone and 
transversly isotropic properties of cancellous bone. Most of the researchers have used the Young's modulus of $13700 \mathrm{Mpa}$ and Poisson's ratio of 0.3 for cortical bone, for cancellous bone Young's modulus has been given the value of $1370 \mathrm{MPa}$ and Poisson's ratio of 0.3 , and for crown the Young's modulus has been given the value of $70000 \mathrm{MPa}$ and Poisson's ratio of 0.19 as shown in Table 1. [5]

Table 1. Mechanical properties of materials

\begin{tabular}{|l|c|c|}
\hline Material & Young's Modulus (MPa) & Poisson's ration \\
\hline Titanium & 110000 & 0.3 \\
\hline cortical & 13700 & 0.3 \\
\hline cancellous & 1370 & 0.3 \\
\hline crown & 70000 & 0.19 \\
\hline
\end{tabular}

\subsection{Loads and boundary conditions}

Mastication involves a repeated pattern of cyclic impacts that causes loading to the implant components and distributes the force to the bone interface. The mean range is found to be 90 to $200 \mathrm{~N}$ depending on the age and gender. But the average force recorded is $116.5 \mathrm{~N}$ in occlusal direction and $40 \mathrm{~N}$ max in the lateral direction. So in current study the load is selected as $116 \mathrm{~N}$ occlusal and $40 \mathrm{~N}$ lateral based on the reported values in literature[6]. The loads and the boundary conditions are applied using the node components created in the pre-processing dedicated software. The bottom nodes of the FE model were fixed to simulate actual conditions.

\section{RESULTS AND DISCUSSION}

\subsection{Assumptions}

The implant-bone is a biological system. It undergoes continuous change as per the response of human body over a period of time. Hence certain assumptions are needed.

3.1.1. 3D section of mandible is taken as bone model with rectangular shape. Rectangle is given height, width and depth of 30x20x10. This assumption with the consideration that focus of analysis is on the stress distribution near implant - bone interface.

3.1.2. Assumption of Isotropic Material Properties: For 3D analysis, isotropic material properties of implant material, cortical bone and cancellous bone are assumed.

3.1.3. Loads: Loads acting on implant vary as per foodstuff position, implant placement etc. Also cyclic loads are common in mastication cycle. For simplification only static vertical and lateral loading has been assumed from the point of view of major component of forces acting on the implant.

The results are been viewed and noted at the neck region of the implant-cancellous bone interface i.e. at the proximal zone. Results are found in the form of stress intensity along the interface as shown in Figure 4 and 5. The corresponding stress intensities are shown in the Table 2.

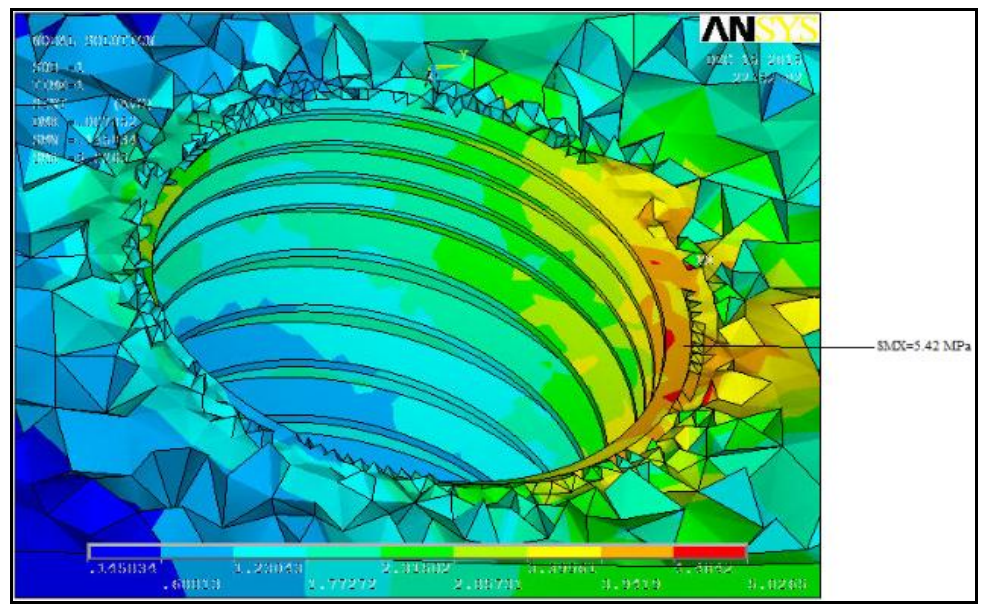




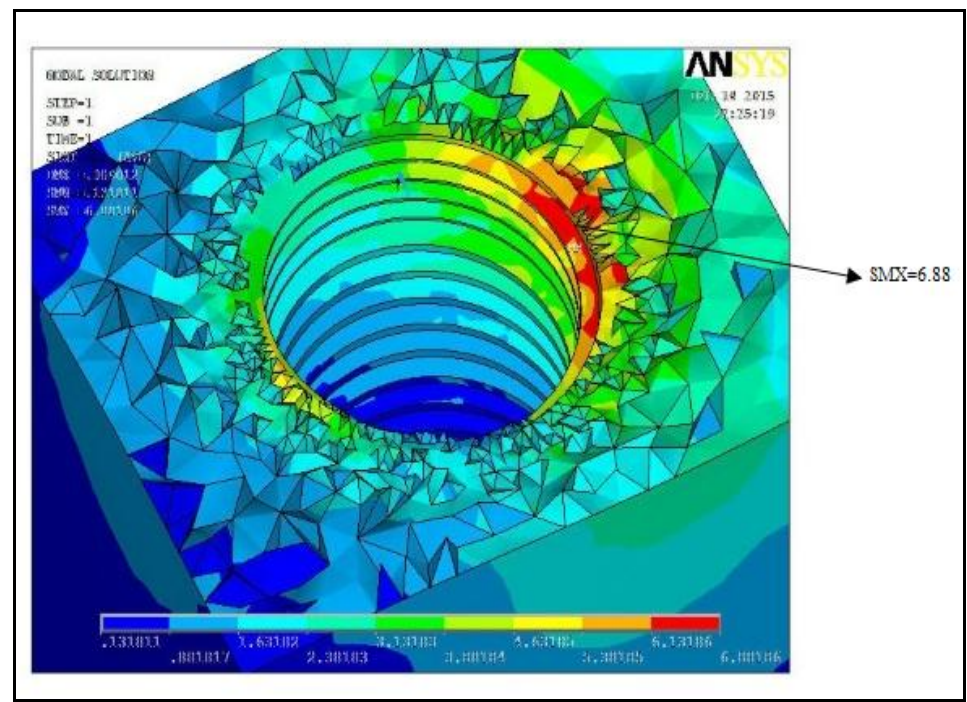

Fig. 4. Stress intensity for model 1 and 2 resp. at the neck region i.e. proximal zone
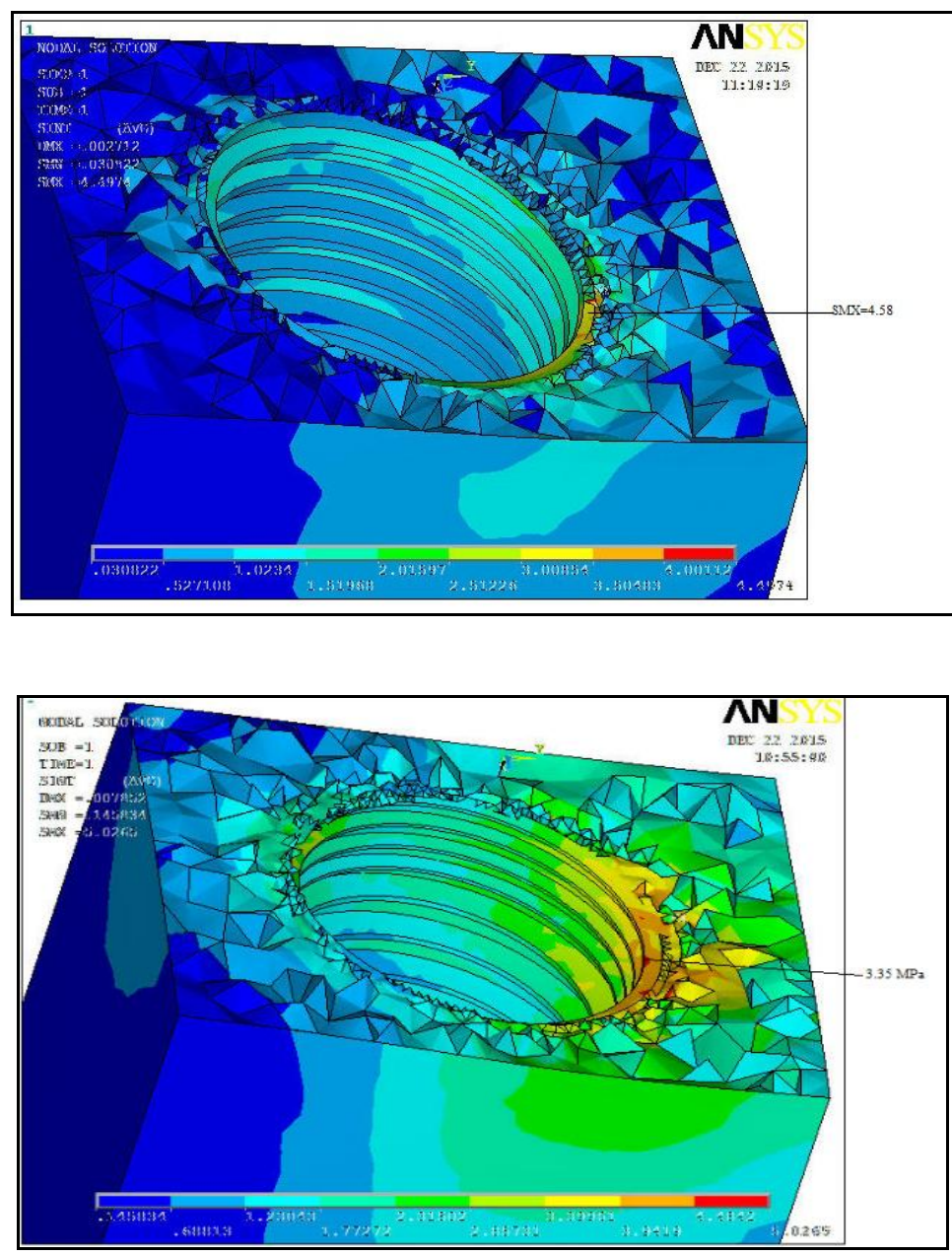

Fig. 5. Stress intensity for model 3 and 4 resp. at the neck region i.e. proximal zone

Table 2. Stress intensity by FEA

\begin{tabular}{|c|c|c|}
\hline Model & Region in bone & Stress \\
\hline
\end{tabular}




\begin{tabular}{|c|l|c|}
\hline \multirow{2}{*}{1} & & Intensity(MPa) \\
\hline \multirow{2}{*}{1} & Proximal (Right) & 5.42 \\
\cline { 2 - 3 } & Proximal (Left) & 5.38 \\
\hline \multirow{2}{*}{2} & Proximal (Right) & 5.38 \\
\cline { 2 - 3 } & Proximal (Left) & 6.88 \\
\hline \multirow{2}{*}{3} & Proximal (Right) & 4.58 \\
\cline { 2 - 3 } & Proximal (Left) & 2.05 \\
\hline \multirow{2}{*}{4} & Proximal (Right) & 1.09 \\
\cline { 2 - 3 } & Proximal (Left) & 3.35 \\
\hline
\end{tabular}

Current study is done to investigate the best thread profile which will give the minimum stress along the implant-bone interface and proper stress distribution in the cancellous bone when the implant system is functionally loaded. Now it is seen from the FEA results, the implant with dimensions Dia.3.5x length $10 \mathrm{~mm}$ gives the maximum stresses along the implant bone interface which is not desirable. So parameters of this particular implant system are been studied and varied so as the stresses around the implant bone interface will be minimum. The iterations carried out are displayed in Table 3.

Table 3. Iterations for thread parameters

\begin{tabular}{|c|c|c|c|c|}
\hline $\begin{array}{c}\text { Iteration } \\
\text { No. }\end{array}$ & $\begin{array}{c}\text { Pitch } \\
(\mathbf{m m})\end{array}$ & $\begin{array}{c}\text { Depth } \\
(\mathbf{m m})\end{array}$ & $\begin{array}{c}\text { Thread } \\
\text { Profile }\end{array}$ & $\begin{array}{c}\text { Stress } \\
\text { intensity } \\
(\mathbf{M P a})\end{array}$ \\
\hline 1 & 0.500 & 0.24 & $\mathrm{~V}$ & 7.93 \\
\hline 2 & 0.300 & 0.24 & $\mathrm{~V}$ & 2.34 \\
\hline 3 & 0.300 & 0.15 & $\mathrm{~V}$ & $\mathbf{2 . 2 9}$ \\
\hline 4 & 0.700 & 0.35 & $\mathrm{~V}$ & 7.69 \\
\hline 5 & 0.478 & 0.25 & Square & 3.53 \\
\hline 6 & 0.478 & 0.25 & Buttress & 2.62 \\
\hline
\end{tabular}

From the Figure no. 6 it can be seen that the iteration no. 3 with pitch of $0.3 \mathrm{~mm}$ and depth of thread $0.15 \mathrm{~mm}$ gives the minimum stress intensity.

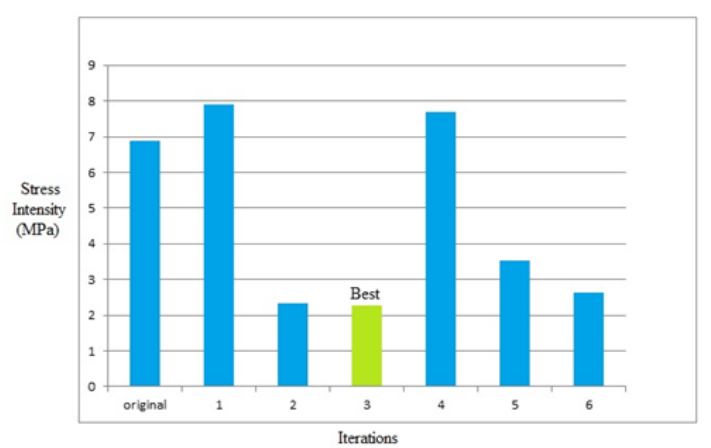

Fig. 6. Stress intensity for various iterations 


\section{CONCLUSION}

The methodology used was stress analysis using FEA. Based on the results of these analyses conclusions can be drawn regarding the effect of the thread depth, pitch on stress distribution.

The implants with different thread profiles parameters were compared for maximum stress intensity at implant bone interface. Stresses were evaluated at proximal left and right regions. Within the limitations of study following conclusions can be drawn.

1. It is found from finite element analysis that the high stress intensity of $6.88 \mathrm{MPa}$ is observed in the areas of bone which are closer to the dental implant, and decrease in magnitude towards the outer region.

2. Stress distribution is uniform in the dental implants along the implant-bone interface.

3. Stress around the implant-bone interface decreases with decrease in pitch and hence the implants with the small pitch, more threads, should be prefered for clinical use.

\section{REFERENCES}

[1] Samira Faegh, Hsuan-Yu Chou and Sinan Mu $\square \mathrm{ftu}$ (2011). Load Transfer Along the Bone-Implant Interface and Its Effects on Bone Maintenance, Implant Dentistry - A Rapidly Evolving Practice, Prof. Ilser Turkyilmaz (Ed.), ISBN: 978-953-307-658-4, InTech, Available from: http://www.intechopen.com/books/implant-dentistry-arapidly- Evolving-practice/load-transfer-alongthe-bone-implant-interface-and-its's-effects-on-bone-maintenance

[2] Luigi Baggi, DDS, Ilaria Cappelloni, MS, Michele Di Girolamo, DDS, Franco Maceri, MS, and Giuseppe Vairo, MS, PhD. The influence of implant diameter and length on stress distribution of Osseo integrated implants related to crestal bone geometry: A three dimensional finite element analysis. December 2008, Volume 100 Issue 6, 422-431

[3] Carlos Nelson Elias (2011). Factors Affecting the Success of Dental Implants, Implant Dentistry - A Rapidly Evolving Practice, Prof. Ilser Turkyilmaz (Ed.), ISBN: 978-953-307-654, InTech, Available from: http://www.intechopen.com/books/implantdentistry-a-rapidly-evolving-practice/factors-affecting-the-successof-dental-implants.

[4] Cheng Xiao Ling, Influence of Bone Quantity and Quality on Stress Distribution in a Maxillary Implant-supported Overdenture: A 3-Dimensional Finite Element Analysis, Department of Mechanical Engineering, National University of Singapore, Session $2006 / 2007$.

[5] N. Djebbar, B. Serier, B. Bachir Bouiadjra *, S. Benbarek, A. Drai. Analysis of the effect of load direction on the stress distribution in dental implant. Materials and Design 31 (2010) 2097-2101

[6] O. Kayabasi et al., "Static, dynamic and fatigue behaviors of dental implant using finite element method," Advances in Engineering Software, vol. 37, pp. 649-658, 2006.

[7] Meijer HJ, Starmans FJ, Bosman F, Steen WH. A comparision of three finite element models of an edentulous mandible provided two implants. Journal of Oral Rehabil 1993; 20:147-157.

[8] S. Hansson and M. Werke, The implant thread as a retention element in cortical bone: the effect of thread size and thread profile: a finite element study. Journal of. Biomech, vol. 36, pp. 1247-58, 2003.

[9] Misch CE. Contemporary implant dentistry. 2nd ed. St. Louis: Mosby; 1999 